\title{
Efek Duty Cycle Pwm pada Pengendalian Kecepatan Motor BLDC 3 Phasa
}

\author{
Rozlinda Dewi \\ ${ }^{1}$ Jurusan Teknik Listrik, Fakultas Teknik, Universitas Batanghari \\ *Corresponding author, e-mail: rozlinda.dewi@gmail.com
}

\begin{abstract}
Abstrak
Dewasa ini hampir seluruh peralatan konveris listrik menjadi gerak manggunakan motor Brushless Direct Current (BLDC), hal tersebut karena motor BLDC memiliki efesiensi dan densitas energi yang tinggi dikarenakan tidak adanya sikat membuat motor BLDC cukup handal, pemeliharaan yang murah dan dapat digunakan untuk kecepatan tinggi. Penelitian ini lebih menekankan pada unit kontroller menggunakan IC DRV 11873 yang mempunyai EVM (Evaluation Module) sebagai penambah kuat induksi magnet pada belitan motor BLDC (stator) dengan mode duty cycle PWM(Pulse Width Modulation), hasil penelitian menunjukan hubungan antara penambahan duty cycle $P W M$ dan penambahan besar tegangan catu daya (V) yang diberikan pada motor BLDC 3 Phasa terhadap perubahan kecepatan motor (RPM). Melalui perhitungan koefisien determinasi $\left(\mathrm{R}^{2}\right)$ tiap hasil percobaan antara perubahan tegangan catu daya $(\mathrm{V})$ terhadap kecepatan (RPM) didapat 0,998 dan hasil perhitungan koefisien determinasi $\left(\mathrm{R}^{2}\right)$ perubahan duty cycle sinyal PWM terhadap kecepatan (RPM) didapat 0,996
\end{abstract}

Kata Kunci : DRV 11873, Kecepatan (RPM), duty cycle PWM

\begin{abstract}
Nowadays almost all electric convertible equipments are in motion using Brushless Direct Current $(B L D C)$ motors, because BLDC motors have high efficiency and energy density because the lack of brush makes BLDC motors reliable enough, maintenance is cheap and can be used for high speed. This research is more emphasized on the controller unit using DRV 11873 IC which has EVM (Evaluation Module) as strong magnetic induction enhancer in BLDC motor winding (stator) with Pulse Width Modulation (PWM) duty cycle mode, the result of research shows the relationship between the addition of duty cycle PWM and the addition of a large supply voltage $V(V)$ given to the 3 phase Phas motor BLDC to the motor speed change (RPM). Through the calculation of coefficient of determination (R2) each experimental results between the change of power supply voltage $(V)$ to the speed (RPM) obtained 0.998 and the calculation of coefficient of determination (R2) change duty cycle PWM signal to the speed (RPM) 0.996
\end{abstract}

Keywords : DRV 11873, Speed (RPM), PWM duty cycle

\section{PENDAHULUAN}

Dilihat dari aspek teknologi, perkembangan motor listrik DC telah mengalami perkembangan sampai pada Brushless Direct Current (BLDC). Sejarah perkembangan motor BLDC diawali dengan ditemukannya magnet permanen pada tahun 1980-an, pada akhir tahun 1980-an Robert E. Lordo dari POWERTEC Industri Corporation menciptakan motor BLDC dengan ukuran lebih besar dari sebelumnya yang telah dikembangkan, Kekuatan yang dimiliki hampir mencapai sepuluh kali kekuatan brushless Direct Current motor yang sebelumnya. Aplikasi motor ini diterapkan dikembangkan di industri sebagai motor linear, motor servo sebagai mesin servo atau penggerak pada robot, aktuator untuk robot di industri[1].

Pada saat ini hampir semua peralatan yang menggunakan konversi listrik menjadi gerak, telah memanfaatkan motor BLDC. Hal tersebut karena BLDC memiliki efisiensi dan densitas energi yang tinggi. Tidak adanya sikat juga membuat motor BLDC cukup handal, pemeliharaan yang murah dan dapat digunakan untuk kecepatan tinggi. umumnya pada motor BLDC untuk pengaturan kecepatan korelasi frekuensi $P W M$ pengaturan duty cycle sangat berperan pada perubahan kecepatan rangkaian kontrol speed drive, dimana pada rangkaian kontrol speed drive dipengaruhi oleh besarnya catu daya listrik untuk memberikan konsumsi pada motor BLDC. Pada penelitian ini sampel 
yang menjadi objek penelitian adalah seberapa besar perubahan duty cycle mempengaruhi perubahan kecepatan motor BLDC dan seberapa besar perubahan catu daya mempengaruhi kecepatan motor BLDC, variansi dari masing-masing perubahan dilakukan dengan uji beda.

\section{TINJAUAN PUSTAKA}

Motor BLDC memiliki struktur pada rotor terdapat magnet permanen dengan kutup yang berselang-seling sementara stator tersusun dari kumparan yang terbagi dalam tiga bagian dengan pola yang sesuai dengan pola magnet permanen, ketiga bagian kumparan tersebut akan dibentuk menjadi sambungan bintang atau delta, untuk mendapatkan putaran motor maka stator pada motor BLDC perlu mendapatkan catu daya listrik yang sesuai untuk menimbulkan medan maget sehingga kutup magnet permanen pada rotor motor BLDC mendapatkan gaya tolak yang diakibatkan kumparan stator, Pola pengkontrolan catu daya pada setiap kumparan motor BLDC adalah dengan mengubah sumber daya DC menjadi daya dalam bentuk sinyal pulsa-pulsa.

\subsection{Cara Kerja Motor BLDC 3 phasa}

Motor BLDC dapat bekerja ketika stator yang terbuat dari kumparan diberikan arus 3 phasa, akibat arus yang melewati kumparan pada stator maka timbul induksi magnet (B) :

$$
B=\frac{\mu N I}{2 L}
$$

dimana:

$$
\begin{aligned}
& \mathrm{B}=\text { induksi magnet }(\text { Tesla }) \\
& \mu=\text { permeabilitas ruang hampa }\left(4 \pi 10^{-7}\right. \\
& \quad \text { Wb/A) } \\
& \mathrm{N}=\text { adalah jumlah lilitan } \\
& \mathrm{I}=\text { adalah Arus }(\mathrm{A}) \\
& \mathrm{L}=\text { adalah panjang lilitan }(\mathrm{m})
\end{aligned}
$$

karena arus yang diberikan berupa arus AC 3 phasa, nilai medan magnet dan polaritas setiap kumparan akan berubah-ubah setiap saat akibat yang ditimbulkan dari adanya perubahan polaritas dan besar medan magnet tiap kumparan maka terjadi medan putar dengan kecepatan $\left(\mu_{s}\right)$ sebesar :

$$
\mu_{s}=\frac{120 f}{P}
$$

dimana :

$$
\begin{aligned}
& \mu_{\mathrm{s}}=\text { kecepatan }(\mathrm{RPM}) \\
& \mathrm{f}=\text { frekuensi arus input }(\mathrm{Hz}) \\
& \mathrm{p}=\text { jumlah kutup }
\end{aligned}
$$

kontruksi rotor dan stator (phasa A, Phasa B dan Phasa C) motor BLDC diperlihatkan pada gambar 1. dibawah.

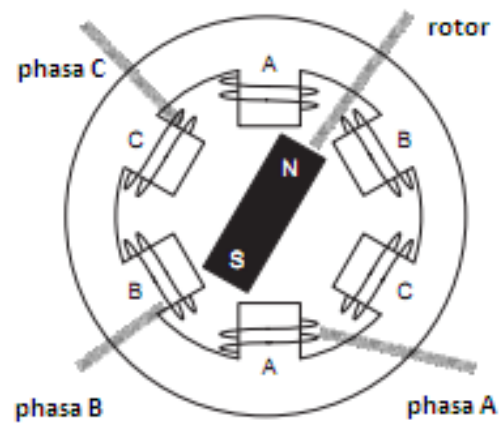

Gambar 1. Kontruksi Motor BLDC[2]

\subsection{Topologi Rangkaian Driver Tiga Phasa}

Untuk mendapatkan putaran pada motor BLDC maka diperlukan rangkaian driver tiga phasa untuk masing- masing kumparan motor, topologi dari rangkaian driver seperti ditunjukan pada gambar 2. dibawah.

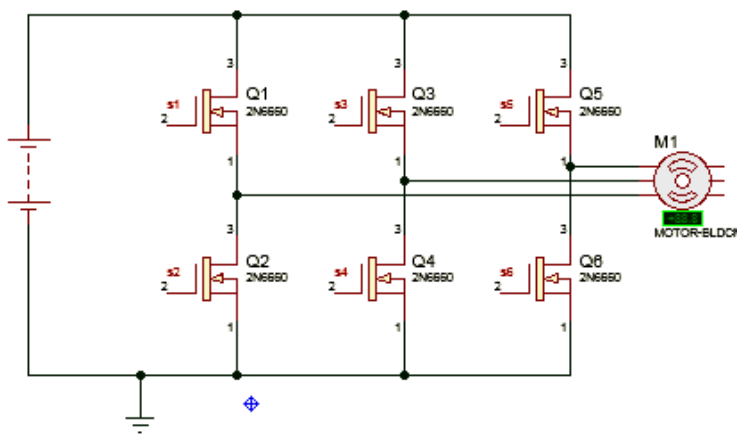

Gambar 2. Topologi Rangkaian Driver 3 Phasa.

dari gambar 2. diatas, komponen saklar daya membutuhkan sinyal $P W M$ untuk mencacah gelombang DC dari catu daya sehingga akan membentuk gelombang AC 3 phasa untuk 
memutar motor BLDC. Adapun bentuk dari sinyal $P W M$ satu phasa ditunjukan seperti gambar 3. dibawah. Sinyal PWM merupakan mode pensaklaran pada komponen saklar daya untuk membentuk keluaran 3 phasa yang dikonsumsi motor BLDC 3 phasa. Mode pensaklaran diperlihatkan pada tabel 1 dibawah.

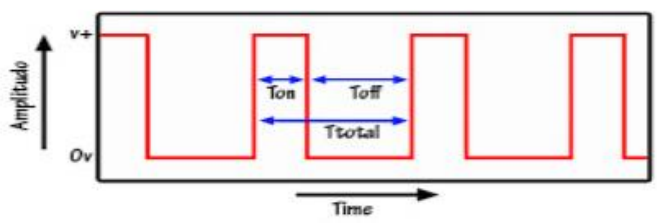

Gambar 3. Sinyal $P W M[3]$

secara matematis persamaan dari sinyal $P W M$ dapat ditulis:

$$
\begin{aligned}
& T_{\text {total }}=T_{o n}+T_{o f f} \\
& D=\frac{T_{\text {on }}}{T_{\text {total }}} \\
& V_{\text {out }}=D x V_{\text {in }} \\
& V_{\text {out }}=\frac{T_{\text {on }}}{T_{\text {total }}} \times V_{\text {in }}
\end{aligned}
$$

\subsubsection{Mode Pensaklaran PWM}

Dari gambar 2 diatas dapat terdapat 6 buah saklar daya masing-masing 3 batas atas dan 3 batang bawah, 3 batas atas terdiri dari S1, S3 dan S5 sedangkan batas bawah terdiri dari S2, S4 dan S6. pola pensaklaran diperlihatkan pada tabel 1 dibawah.

Tabel 1. Mode Pensaklaran BLDC 3 Phasa[4]

\begin{tabular}{cccccc} 
S1 & S3 & S5 & S2 & S4 & S6 \\
\hline ON & OFF & OFF & OFF & ON & OFF \\
ON & OFF & OFF & OFF & OFF & ON \\
OFF & ON & OFF & ON & OFF & OFF \\
OFF & ON & OFF & OFF & OFF & ON \\
OFF & OFF & ON & ON & OFF & OFF \\
OFF & OFF & ON & OFF & ON & OFF \\
\hline
\end{tabular}

\section{METODOLOGI}

Penelitian ini dilakukan dengan uji perangkat keras menggunakan motor BLDC kapasitas 12V/1,8A 3 phasa, sedangkan Driver set menggunakan adjustable $P W M$ brussless $(5 \mathrm{~V}-16 \mathrm{~V}) / 1,8 \mathrm{~A}$ (DRV11873).

\subsection{Perancangan dan Pengambilan Data}

Pada penelitian ini berdasarkan dari prinsip kerja motor BLDC, parameter-parameter yang mempengaruhi besar kecepatan (RPM) adalah : sinyal Pulsa dan kapasitas tegangan Catu daya (Volt). sinyal pulsa merupakan Evaluation Module (EVM) pada driver set DRV 11873 untuk tambahan tenaga pada bilitan motor atau menambah kuat induksi magnet (B) yang dibangkitkan sedangkan tegangan catu daya (V) adalah besar potensial tegangan yang diberikan pada belitan motor BLDC 3 Phasa, diagram alur penelitian diperlihatkan seperti gambar 4. dibawah.

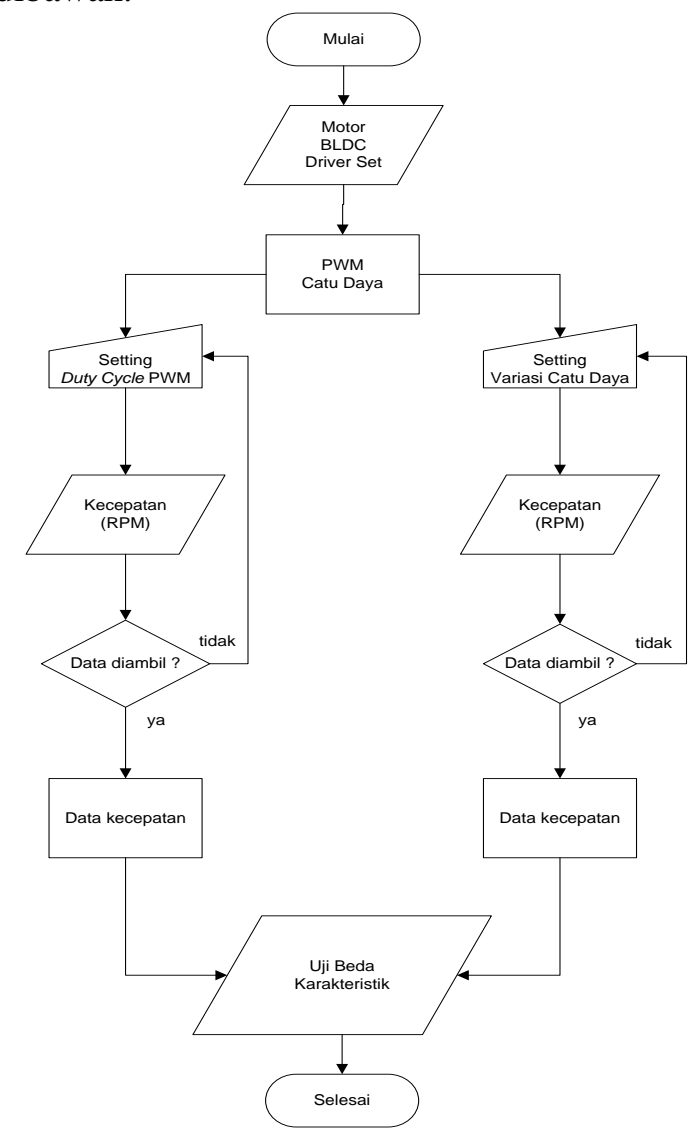

Gambar 4. Alur Penelitian

\subsection{Pengolahan data}

Data yang diolah adalah membandingkan antara besar duty cycle sinyal $P W M$ terhadap peubahan kecepatan motor BLDC (RPM) dan 
perubahan besar tegangan catu daya (V) terhadap perubahan kecepatan motor BLDC (RPM), dengan asumsi perubahan duty cycle sinyal pulsa dan perubahan besar catu daya yang diberikan akan dijadikan variabel pada penelitian.

\section{HASIL DAN PEMBAHASAN}

Unjuk kerja perangkat keras pada penelitian ini adalah memaksimalkan kecepatan dari Motor BLDC dan seberapa besar perubahannya terhadap input pengerak yang diberikan (tegangan dan duty cycle). Driver set yang digunakan untuk mengerakan motor BLDC 3 phasa ditunjukan pada gambar 8 dibawah.

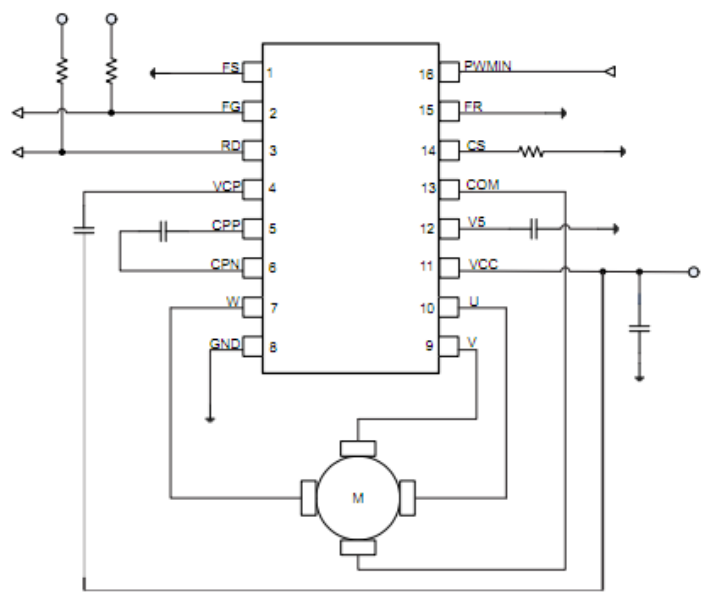

Gambar 8. Topologi Rangkaian Driver 3 Phasa[5].

Driver DRV 11873 adalah driver motor BLDC 3 phasa tanpa sensor, DRV 11873 merupakan sebuah chip yang mempunyai 16 kaki dimana masing-masing kaki mempunyai fungsi dan karakteristik sesuai dengan konfigurasinya. Untuk mendapatkan putaran motor, kaki 1 (FS) dihubungkan ke ground akan mendapatakan putaran rendah dan jika diberikan tegangan 5 volt melalui resistor pull up $(10 \mathrm{k} \Omega)$ akan mendapatkan putaran tinggi , kaki 2 (FG) adalah frekuensi generator pada penelitian ini dihubungkan ke sumber tegangan 5 volt melalui resistor pull up (100 $\mathrm{k} \Omega)$, kaki 3 (RD) adalah deteksi putaran pada motor dari driver pada penelitian ini dihubungkan ke sumber tegangan 5 volt melalui resistor pull up $(100 \mathrm{k} \Omega)$, kaki 14 (CS) adalah sensor arus pada penelitian ini dihubungkan ke ground melalui resistor $(4,7 \mathrm{k} \Omega$ ), kaki 12 (V5) adalah kaki sumber logik dari chip IC DRV 11873 pada penelitian ini dberikan sumber tegangan 5 volt, kaki 11 (VCC) adalah tegangan catu daya yang diberikan untuk motor BLDC melalui chip DRV 11873 variasi besar tegangan yang dapat diberikan adalah 5 Volt sampai 16 Volt dan kaki 16 (PWMIN) adalah masukan sinyal PWM dengan frekuensi $25 \mathrm{Khz}$ pada penelitian ini sinyal PWM dibangkitkan menggunakan IC TL 494 dengan duty cycle 5\% - $95 \%$.

\subsection{Tegangan (volt) vs Kecepatan(RPM)}

Pengamatan terhadap besar kecepatan motor BLDC 3 phasa terhadap perubahan kenaikan tegangan catu daya (V) adalah dengan memberikan variasi tegangan (Volt) pada kaki 15 (VCC) DRV 11873 (driver set), hasil penelitian diperlihatkan pada tabel 1 dibawah, dimana dalam pengambilan data duty cycle sinyal $P W M$ pada unit driver set disetting $50 \%$ konstan, kemudian tegangan catu daya (V) yang masuk sebesar 5 volt dan dinaikan dengan variasi penambahan sebesar 2 Volt setiap pengambilan data kecepatan motor BLDC.

Tabel 2. Parameter Catu Daya dan Kecepatan

\begin{tabular}{ccc}
\hline NO & Catu Daya (V) & Kecepatan (RPM) \\
\hline 1 & 5 & 11300 \\
2 & 7 & 14500 \\
3 & 9 & 16400 \\
4 & 11 & 18700 \\
5 & 13 & 20600 \\
\hline
\end{tabular}

dari tabel diatas dibuat grafik lengkug kecepatan motor BLDC untuk mendapatkan koefisien determinasi dari setiap pengambilan data yang didapat, grafik lengkung tegangan vs kecepatan diperlihatkan pada gambar 5 dibawah.

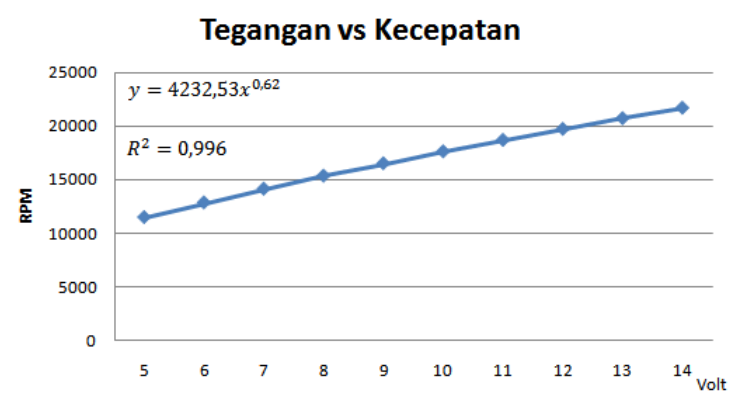


Gambar 5. Grafik lengkung Tegangan vs Kecepatan

\subsection{Duty Cycle vs Kecepatan(RPM)}

Pengamatan terhadap besar kecepatan motor BLDC 3 phasa terhadap perubahan duty cycle sinyal $P W M$ diperlihatkan pada tabel 1 dibawah, dimana dalam pengambilan data besar tegangan catu daya $(\mathrm{V})$ yang diberikan sebesar 5 Volt, sedangakan duty cycle sinyal $P W M$ pada unit driver set disetting mulai dari $15 \%$ dengan variasi penambahan duty cycle sebesar $20 \%$ tiap pengambilan data kecepatan, bentuk gelombang sinyal $P W M$ yang dihasilkan dari unit driver set masing-masing ditunjukan pada gambar 6 dibawah.

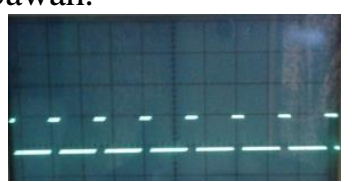

(a) Duty Cycle $15 \%$

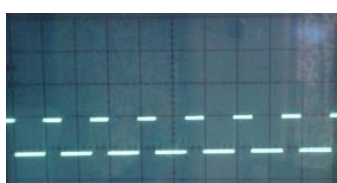

(b) Duty Cycle 35\%

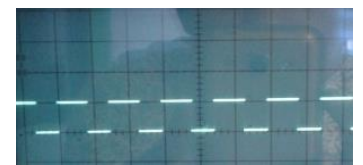

(c) Duty Cycle 55\%

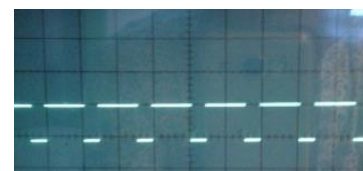

(d) Duty Cycle $75 \%$

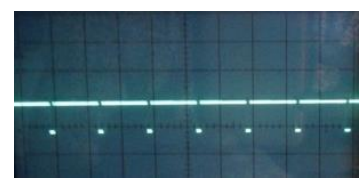

(e) Duty Cycle 95\%

Gambar 6. Duty Cycle Sinyal PWM
Tabel 3. Parameter Duty Cycle dan Kecepatan

\begin{tabular}{ccc}
\hline NO & Duty Cycle (\%) & Kecepatan (RPM) \\
\hline 1 & 15 & 3000 \\
2 & 35 & 6500 \\
3 & 55 & 11400 \\
4 & 75 & 15700 \\
5 & 95 & 17800 \\
\hline
\end{tabular}

dari tabel diatas dibuat grafik lengkug kecepatan motor BLDC untuk mendapatkan koefisien determinasi dari setiap pengambilan data yang didapat, grafik lengkung duty cycle vs kecepatan diperlihatkan pada gambar 7 dibawah.

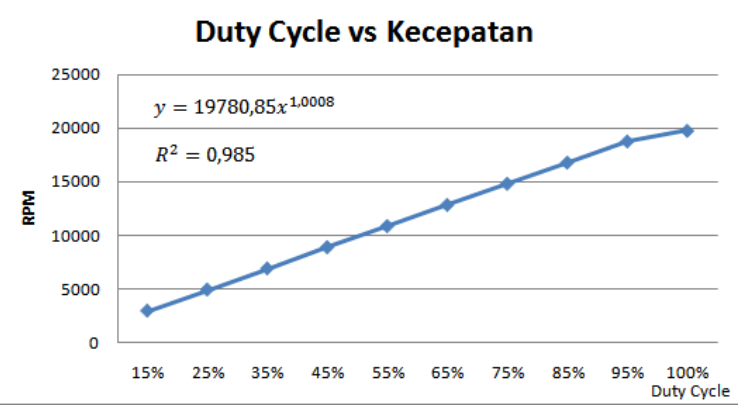

Gambar 7. Grafik lengkung Duty Cycle vs Kecepatan

\section{SIMPULAN}

Berdasarkan hasil penelitian dapat disimpulkan sebagai berikut:

1. Perubahan kecepatan (RPM) dengan penambahan besar tegangan $(\mathrm{V})$ mempunyai koefisien determinasi (korelasi) yang lebih besar dibandingkan dengan perubahan kecepatan dengan penambahan besar duty cycle sinyal PWM.

2. Untuk perancangan pengaturan kecepatan motor BLDC 3 phasa lebih efektif dengan pengaturan besar duty cycle sinyal PWM pada besar tegangan catu daya $(\mathrm{V})$ tertentu untuk memberikan konsumsi daya yang lebih kecil.

\section{DAFTAR PUSTAKA}

[1] Abe Dharmawan, 2009, Pengendalian Motor Brushless DC dengan Metode PWM Sinusoidal 
menggunakan Atmega 16, skripsi, Fakultas Teknik Universitas Indonesia, Depok

[2] Cosmas Tatenda .K., Vlnukumar .L, \&Nurul Shahrizan.S, Effect Of Pulse Width Modulation On DC Motor Speed, International Journal of Student Research In Technology \& Management., Vol 5 , no. 2, pp. 42-45, 2017.

[3]Texas Instrumen, 2013, Sensorless Trapezoidal Control of BLDC Motors. www.ti.com, (Diakses 26/01/2017 pukul 11.13WIB).

[4]mps, 2014, Brushless DC Motor Fundamental Application Note, www.MonolithicPower.com, (Diakses 23/05/2017 pukul 11.19 WIB)

[5] Texas Instrumen, 2017, DRV 11783 datasheet, www.ti.com/product/DRV11873, (Diakses 26/10/2017 pukul 16.10WIB). 